\title{
ГЕНЕЗИС ФИНАНСОВОГО ОБЕСПЕЧЕНИЯ ЗАКУПОЧНОЙ ДЕЯТЕЛЬНОСТИ В КАНАДЕ
}

\section{GENESIS OF PROCUREMENT FINANCING IN CANADA}

\section{A. Salnikova}

Summary. Based on the historical method, the article reveals the features of the formation and development of financial support for public procurement in Canada, highlights the main political and economic consequences of spending public funds in different periods, gives a description of the current public procurement system in Canada at present.

Keywords: Canada, public procurement, digital economy.
Сальникова Анастасия Игоревна

Аспирант, Российский государственный университет правосудия, (2. Москва) anastasiya-2105@yandex.ru

Аннотация. В статье на основе исторического метода раскрываются особенности становления и развития финансового обеспечения публичных закупок в Канаде, выделены основные политические и экономические последствия расходования публичных средств в различные периоды, дана характеристика сформированной системы публичных закупок в Канаде в настоящее время.

Ключевые слова: Канада, публичные закупки, цифровая экономика. $\mathbf{0}$ собенности исторического развития отношений, возникающих в процессе обеспечения государственных нужд в товарах, работах, услугах, а также финансовые решения, принимаемые в тот или иной исторический период, предопределяют характер и качество этих отношений в будущем, позволяют выявить истинные, глубинные причины успехов и неудач.

Постоянная модернизация системы государственных закупок в России, повсеместная цифровизация экономических процессов и попытки «идти в ногу» с западными коллегами, рождает ряд трудностей, с которыми в свое время уже столкнулись в Канаде. На наш взгляд, важно обратиться к опыту зарубежных государств, которые выработали собственные модели финансового обеспечения закупочной деятельности и успешно их реализуют в течение длительного времени.

Очевидные сходства России и Канады, такие как: большая и неравномерно заселенная территория, ее «северность», богатство и разнообразие природных ресурсов, многонациональное и многоконфессиональное население определяют характер методов государственного управления, а значит и финансовых решений, которые в свою очередь представляют бесспорную ценность для анализа и возможного внедрения в российскую правоприменительную практику.

Стремление населения североамериканских колоний в начале 19 века к финансовой самоорганизации привело к тому, что, Канада, являясь приемником британской парламентской практики, на заре своей истории, стала примером своего рода естественно сформированной финансовой системы сдержек и противовесов, оптимального соотношения полномочий по использованию государственных средств: с одной стороны - самостоятельно сформировавшегося представительного органа, выражавшего интересы населения, в том числе финансовые, с другой - гаранта соблюдения публичных интересов в лице короны.

К моменту образования Конфедерации народные собрания британской Северной Америки отстояли свое право решать, какие налоги следует собирать и на что они будут тратиться, следуя принципу «ответственного правительства», согласно которому исполнительная власть может управлять только тогда, когда пользуется доверием и поддержкой Палаты общин. [1, с. 12]

Правила 1867 года требовали, чтобы финансовые вопросы рассматривалась сначала в Комитете полного состава, а затем обсуждалась в палате.[2] Это было сделано для того, чтобы «парламент не мог путем внезапных и поспешных голосований нести какие-либо дополнительные расходы или быть вынужденным утвердить меры, которые могут повлечь за собой тяжелые и длительные осложнения для страны». Все резолюции или законопроекты, касающиеся расходования государственных средств, должны были быть сначала рекомендованы Генерал-губернатором. [1, с. 404-405]

Еще одной мерой, защищающей Палату от поспешных финансовых решений, было правило, что обсуждение любого предложения «для любой общественной помощи или поручения народу», не будет произведено немедленно, а будет перенесено на следующий день за- 
седания. [2] Это было сделано для того, чтобы «ни один член не мог быть вынужден принять поспешное решение, но каждый мог иметь возможность излагать свои доводы для поддержки или противодействия предлагаемому гранту».[1, с. 462-463]

Как мы видим, еще одним преимуществом наследования британских парламентских процедур стали для Канады веками отработанные принципы расходования бюджетных средств, детализированные и регламентированные процессы принятия финансовых решений, а также предупреждение поспешности и неосторожности в данных вопросах.

Строительство нации подразумевало закупки в больших масштабах и включало в себя различные формы закупок, зачастую, это были договоры с частными предприятиями, в режиме максимального государственного благоприятствования. Финансирование строительства основных транспортных систем: железные дороги, трубопроводы и морской путь Св. Лаврентия, явились также безусловным фактором для объединения провинций в союз и сокращения экономического неравенства между регионами.

Особый интерес представляет процесс зарождения прототипа современных государственных частных партнерств, представляющих на тот момент, помимо крупных государственных субсидий транспортным предприятиям, безвозмездную передачу земельных участков вдоль объектов транспортной инфраструктуры, при этом правительство обещало компаниям в течение 20 лет не допускать создания параллельных путей вдоль возводимых магистралей, а до начала выплат дивидендов, правительство не имело право регулировать цены на проездные билеты.[3, с. 103]

Закупки для обороноспособности и защиты канадцев в период Первой мировой и Второй мировой войны во многом способствовали общему развитию промышленности. Увеличились государственные субсидии на производство вооружения и военной техники. [3, с. 154] Для организации подготовки к войне и удовлетворения растущего спроса правительства на продукты, создавались предприятия различных форм собственности и производства. Правительство Канады посчитало, что может финансировать необходимое массовое строительство и производство дешевле, чем частные промышленники, что стало причиной возникновения частно-государственных отраслей промышленности и машиностроения.

Военные потрясения стали для канадской экономики мощным стимулом развития публичных закупок, перевод производства на военные рельсы сопровождался резким повышением государственного спроса, и, как следствие, производственной активностью частных предприятий.

Послевоенная страна извлекла выгоду из усилий организации военного времени с точки зрения твердого институционального фона. Политика справедливой заработной платы 1954 г. уполномочила федеральное правительство отдавать предпочтение отечественным фирмам и отечественному труду в своей политике закупок. [4, с. 448-450] Использование закупок для других целей, помимо рентабельного приобретения было оправдано с точки зрения занятости, технологии, баланса платежей и безопасности поставок. Присуждение контрактов фирмам с высоким риском безработицы начали появляться в форме региональной политики с экономическими и социальными целями. [5, с. 7] Предоставление правительственных контрактов фирмам в маргинальные избирательные округа стало способом поддержки предложений о переизбрании.

Внимание к политике регионального развития было связано с угрозой национальному единству. В 1957 году федеральное правительство начало программу фискального выравнивания. Эта программа была нацелена на сокращение различий между регионами, на достижение национального стандарта в сфере государственных услуг и в то же время на выравнивание доходов провинциального правительства. В провинциях росло стремление к тому, чтобы федеральные закупки товаров и услуг равномерно распределялись между регионами. [6, с. 161]

Например, государственный бюджет 1960 года позволил фирмам получить двойную норму расходов на большую часть активов, если они расположены в определенных регионах (с высоким уровнем безработицы и медленным экономическим ростом).[7, с. 278]

Минимальная вовлеченность в военные действия и мягкие меры по возвращению производства на мирные рельсы в сохранившейся в первозданном виде Канаде, сочетающиеся с продолжающимся процессом развития регионов и инфраструктуры страны, позволили Канаде в послевоенный период с наименьшим сопротивлением внешним обстоятельствам продолжить совершенствовать систему государственных закупок, а также активно использовать закупочную деятельность в политических целях укрепления государственного единства.

Утверждённая в 1988 года политика правительства Канады «Повестка дня для дальнейшего процветания» продолжила использование закупок для поддержки регионов. Были приняты меры по увеличению доли государственных закупок на западе страны, в атлантическом регионе. В Северном Онтарио, учредили программу 
Access Small Business, целью которой стало внедрение новых функций субподряда и развития поставщиков для крупных фирм, претендующих на государственные контракты, что позволило малым предприятиям в регионах получать больше выгоды от государственных закупок, а такие административные меры, как ротация заявок и региональные ярмарки поставщиков, позволили местным малым предприятиям расширить возможности подавать заявки на государственные контракты.

В рамках проводимых региональных мероприятий были утверждены принципы закупок, параллельно с внедрением понятия «географическая нейтральность», суть которого как раз заключалась в обеспечении действия всех юрисдикций на основе одних и тех же основных принципов.[8, с. 143] Этими принципами были: принцип доступности, обеспечивающий равный доступ к контрактным возможностям для заинтересованных фирм; принцип конкуренции, обеспечивающий честный процесс приобретения, на конкурентной основе соответствующей эффективной и рентабельной системе закупок; принцип непротиворечия географической нейтральности, позволяющий учесть возможности участия всех заинтересованных и квалифицированных поставщиков, где бы они ни находились; принцип транспарентности, допускающий формирование конкретной политики или практики закупок в качестве исключения из принципов географической нейтральности, требующий, при этом, ясного определения, обнародования и четкого формулирования такой политики и практики.

Стоит отметить, что в данный период наряду с признанием и попытками систематизировать более открытые и прозрачные методы закупок (например, первые попытки начать стандартизацию кодирования и качества), с утверждением принципов закупок, нарастали противоречия между реализацией данных принципов и политикой, которую продвигали правительства.[8, с. 144] Данные процессы, как нам видится, отражают естественную реакцию системы, подвергнувшейся системным изменениям.

Параллельно с политикой развития регионов, продолжалась использование закупок для развития сильного оборонного потенциала в период холодной войны на основе институциональных связей с Соединенными Штатами.

До конца 1980-х годов закупки использовались, главным образом, в качестве распределительного инструмента, так как служили целям политических игроков получения благосклонности избирателей путем перераспределения средств в конкретные области (и обеспечения непрерывности финансирования программ), очень сильный рычаг, с помощью которого можно напра- вить и реализовать экономические и социальные идеи и планы. При этом, сформировавшаяся необходимость в выработке принципов публичных закупок свидетельствует об уровне зрелости правовой системы в данный период. Помимо всего прочего, использованию закупок для поддержки малого бизнеса и национальных производителей в Канаде стали уделять внимание уже во второй половине 20 века.

Следующим этапом совершенствования системы закупок для государственных нужд в Канаде стал процесс централизации и цифровизации.

Закон о Департаменте общественных работ и государственных услуг (Public Works and Government Services Canada далее PWGSC), принятый в 1996 году, учредил Департамент и определил перечень его полномочий. Закон установил PWGSC в качестве общей сервисной организации, предоставляющей государственным ведомствам и учреждениям услуги поддержки в процессе проведения закупок.

Конфликт интересов в процессе централизации процесса закупок заключался в желании одних достичь максимальной формализации с наименьшей возможностью субъективного усмотрения в условиях обеспечения конкуренции, и, в то же время, других (т.е. представителей развивающихся отраслей или групп с особыми интересами), для которых усмотрение со стороны государственных чиновников и в правилах, важно для развития собственного продукта и поиска рынка сбыта.

В конце 1990-х гг. был сделан акцент на расширении использования Интернета для правительства, бизнеса и частных лиц. К 2003 году Канада заняла первое место в исследованиях Accenture в рейтинге «самых «подключенных» правительств» [8, с. 235].

Потенциал использования ИТ в сфере закупок возрастал и со временем приобрел ключевое значение с точки зрения эффективности и конкурентоспособности не только в частном секторе, но и в управлении программами в государственном секторе.

Опрос сотрудников закупок в 2001 году показал, что онлайн закупок в Канаде было только 5\% от общего объема закупок. Однако, это исследование также показало, что 94\% служащих в сфере закупок использовали Интернет для выявления потенциальных поставщиков, в то время как 90\% использовали Интернет для связи с поставщиками и 89\% использовали его для просмотра электронных каталогов. [8, с. 276]

Растущий технологический потенциал для онлайн-закупок бросил вызов правительственным организацион- 
ным и управленческим моделям, которые имели тенденцию развиваться очень медленно. Как отмечается, устаревший процедурный уклад в условиях нехватки технологических и человеческих ресурсов, не был достаточно развит, чтобы иметь дело с потенциальными возможностями «проводного» мира. [8, с. 236]

Проект Электронной цепочки поставок в PWGSC и служба MERX (онлайн-хранилище возможностей для подачи заявок и документов, доступных для частного сектора со всей страны) были ранними попытками интеграции интернет-технологий с традиционными процессами закупок с разной степенью успеха.

Еще одной проблемой стратегического использования информационных технологий в сфере госзакупок, на тот момент стала неспособность одной организации объединить и создать условия для удовлетворения потребности различных департаментов с использованием онлайн-инструментов.

Еще одной важной чертой закупочного процесса в Канаде является снижение коррупционных рисков. Ключевым этапом реализации Закона о подотчетности, призванного повысить качество подотчетности и способствовать прозрачности деятельности правительства, стало введение в 2007 году Кодекса поведения при закупках. устанавливающий стандарты для должностных лиц, занимающихся закупками, в частности конкретные ограничения и запреты, направленные на обеспечение того, чтобы частные интересы должностных лиц не влияли ненадлежащим образом на выполнение ими своих общественных обязанностей. Кодекс поведения в сфере закупок в Канаде применяется ко всем, кто вовлечен в процесс закупок, - как государственным служащим, так и поставщикам - с четким изложением взаимных ожиданий для обеспечения общего базового понимания среди всех участников закупок.

Кодекс также дополняет и другие меры, объявленные в Федеральном законе о подотчётности - такие, как назначение омбудсмена закупок и независимого советника по практике исследования общественного мнения для укрепления открытости, прозрачности и добросовестности в сфере государственных закупок.

Следует заметить, что, сегодня, правительство ведет активную программу совершенствования системы в целом. В связи с чем, 5 марта 2019 года было объявлено о комплексной программе, получившей название «Лучшие закупки», которая направлена на модернизацию закупочных процессов путем создания современной закупочной базы, обеспечения более простой, гибкой и доступной системы закупок и достижения социаль- но-экономических целей, повышения конкуренции и стимулирования инноваций.

Анализ развития отношений в сфере публичных закупок в Канаде позволяет нам сделать следующие выводы.

Направление финансирования на обеспечение потребностей государства в конкретный исторический период его развития определялось целью стратегического плана по формированию конкретных политических и экономических результатов, что являлось своего рода мерами финансовой поддержки национальной экономики.

Процесс зарождения и развития финансовых правоотношений, в том числе отношений по расходованию средств бюджета на территории современной Канады сопровождался компромиссными решениями между представителями местного населения и Короной, а внедрение многовекового британского опыта финансового обеспечения расходования денежных средств, стало для Канады своеобразным «трамплином» в последующем развитии данных отношений.

Стремительное развитие обширной территории осуществлялось путем вложений денежных средств в стратегически важные сферы экономики. Еще одним важным фактором в формировании государственного устройства будущей федераций стали финансовые вложения в объединение (соединение) отдаленных территорий с центром, в том числе путем использования государственно-частных партнерств при строительстве транспортной инфраструктуры.

Мировые военные потрясения позволили Канаде, продолжить развитие публичных закупок в новых условиях повышенного спроса и стимулирования повышения предложения.

Отсутствие боевых действий на территории Канады позволило обойтись мягкими мерами по возвращению производства на мирные рельсы, при этом, активно продолжить процесс развития государственных закупок в качестве инструмента бюджетного выравнивания, регионального развития и политической агитации.

Продолжительный и достаточный опыт Канады в сфере конкурентных закупок позволил стране уже в 90-е годы приступить к цифровизации данного процесса, и, таким образом, продолжить его совершенствование уже более 20 лет

На наш взгляд, знание истории становления и современного состояния закупочной деятельности государства в Канаде, ее организации могут быть полезными для современной России. Непрекращающееся совершен- 
ствование контрактной системы в нашей стране диктует необходимость во внедрении наиболее эффективных, проверенных моделей финансового обеспечения закупочного процесса. Конечно, слепое заимствование за- падного опыта не сможет решить имеющиеся проблемы. Однако, определенные положительные черты публичных закупок в Канаде могут быть использованы при реформировании отечественной контрактной системы.

\section{ЛИТЕРАТУРА}

1. Sir John George Bourinot, Parliamentary Procedure and Practice in the Dominion of Canada, 4th ed., ed. Thomas Barnard Flint (Toronto: Canada Law Book, 1916$) 693$.

2. Rules, Orders and Forms of Proceeding of the House of Commons of Canada, 1868.

3. Тишков В. А., Кошелев Л. В. История Канады.- М.: Мысль, 1982. - 268.

4. Klaus Stegeman and Keith Acheson, "Canadian Government Purchasing Policy", Journal of World Trade Law 6, No.4 (July-August 1972): 442-478.

5. S. Arrowsmith and K. Hartley, "Introduction” in Sue Arrowsmith and Keith Hartley, eds., Public Procurement — Volume I and Volume 2, The International Library of Critical Writings in Economics (Cheltenham: Edward Elgar Publishing Limited, 2002), 1416.

6. D.J. Savoie, Regional Economic Development: Canada's search for solutions (Toronto: University of Toronto Press, 1992), 342.

7. B. Higgins and D. J. Savoie, Regional development theories \& their application (New Brunswick, New Jersy: Transaction Publishers, 1995), $276-277$.

8. Carleton University Research Virtual Environment B.A.C. Allen Procurement policy in Canada evolution and impacts-domestic policy, trade, and information technology https://curve.carleton.ca/c49bbe21-2bfa-4238-a456-7b992e893d36.

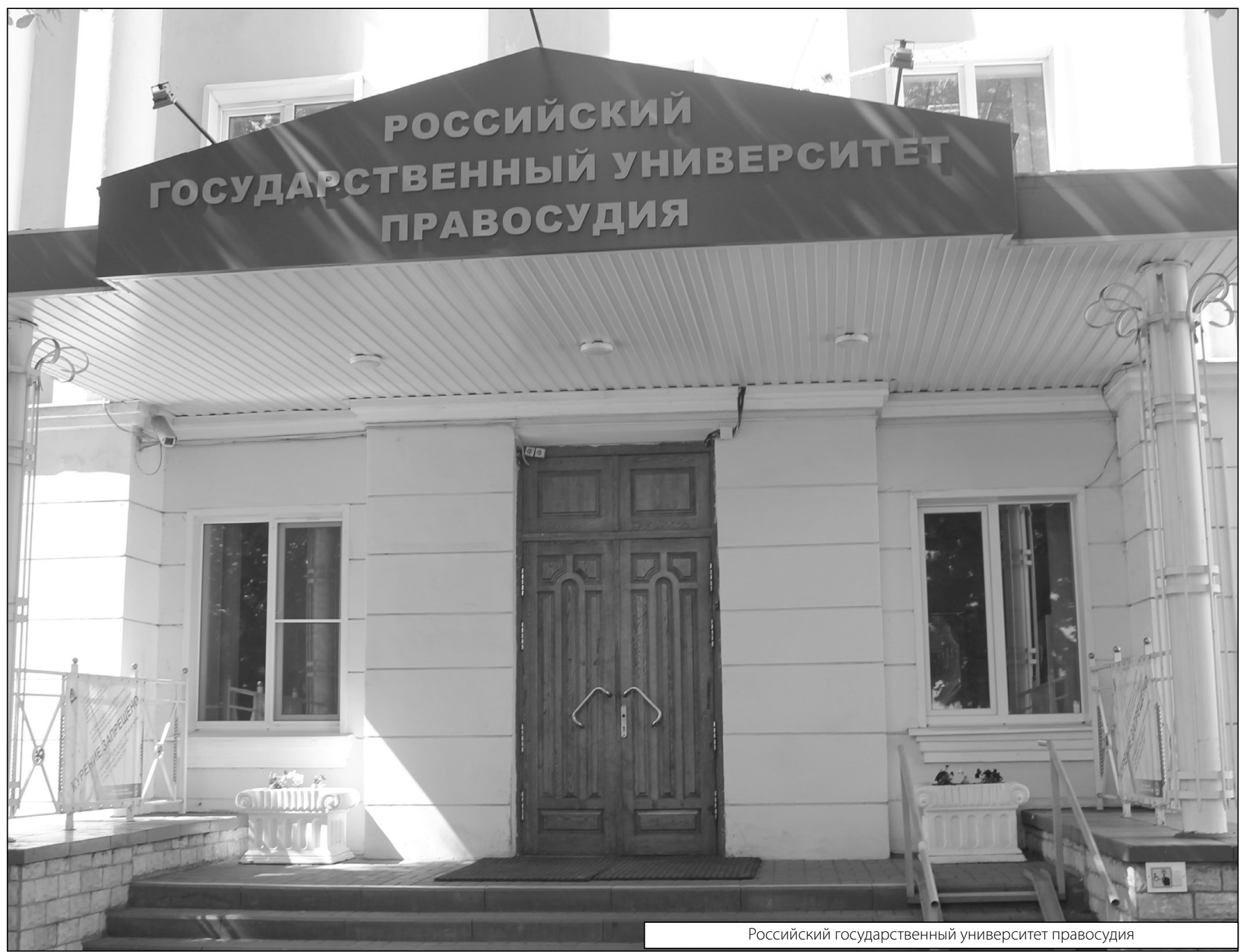

